\title{
Role of Secretory Events in Modulating Human Neutrophil Chemotaxis
}

\author{
John I. Gallin and Daniel G. Wright, Laboratory of Clinical Investigation, \\ National Institute of Allergy and Infectious Diseases, National Institutes of \\ Health, Bethesda, Maryland 20014 \\ ElliotT SCHIFFMANN, Laboratory of Developmental Biology and Anomalies, \\ National Institute for Dental Research, National Institutes of Health, \\ Bethesda, Maryland 20014
}

\begin{abstract}
A B S T RACT The relationship between neutrophil polymorphonuclear leukocyte (PMN) locomotion and the exocytosis of neutrophil cytoplasmic granules was studied by assessing these processes in cells migrating through micropore filters and by measuring the effects of degranulating stimuli on PMN chemotaxis, orientation, adhesiveness, and ability to bind the chemoattractant f-Met-Leu- $\left[{ }^{3} \mathrm{H}\right] \mathrm{Phe}$. Studies of cells migrating through cellulose nitrate filters indicated that concentrations of f-Met-Leu-Phe optimal for exocytosis were greater than those optimal for chemotaxis and actually inhibited cell migration. In other studies incubation of PMNs with concentrations of secretagogues causing exocytosis of $30 \%$ or greater PMN lysozyme increased cell adhesiveness and inhibited chemotaxis. PMNs that had secreted more than $30 \%$ lysozyme appeared round, did not orient in a gradient of chemoattractant, and were capable of significantly less f-Met-Leu- $\left[{ }^{3} \mathrm{H}\right] \mathrm{Phe}$ binding than were control cells. The decreased binding of f-Met-Leu-Phe was not associated with hydrolysis of chemotactic peptide by washed cells, although peptide hydrolysis was caused by cell products secreted extracellularly after vigorous exocytosis. In contrast, when only $10-15 \%$ cellular lysozyme was released f-MetLeu-Phe binding was enhanced significantly and there was no depression of chemotaxis. The data indicate limited exocytosis of intracellular granule contents is associated with increased availability of PMN chemotactic factor receptors. Vigorous exocytosis is associated with inactivation of chemotactic responsiveness re-
\end{abstract}

Dr. Wright's present address is Experimental Hematology Section, Pediatric Oncology Branch, National Cancer Institute, National Institutes of Health, Bethesda, Md. 20014. Address reprint requests to Dr. Gallin.

Received for publication 22 November 1976 and in revised form 16 August 1978. lated to increased cell adhesiveness, decreased PMN binding of chemotactic factors, and to hydrolysis of chemoattractants by factors secreted extracellularly.

\section{INTRODUCTION}

A relationship between neutrophil locomotion and secretion of granule associated enzymes has been indicated by studies from several laboratories (1-5). Most agents that are chemokinetic are also chemotactic and induce exocytosis of cytoplasmic granule enzymes when the leukocyte membrane is perturbed either by adherence to a surface such as a cellulose nitrate filter or by treatment with cytochalasin B (1-3). Furthermore, there is evidence that chemotactic factors stimulate neutrophil locomotion and secretion by interacting with a common membrane receptor, although concentrations of chemotactic factors initiating chemotaxis are significantly lower than concentrations initiating secretion $(4,6,7)$. We have investigated the relationship between neutrophil locomotion and secretion by studying these processes in cells that migrate through cellulose nitrate filters and by studying the effects of degranulating stimuli on cell orientation, chemotaxis, adhesiveness, and the ability of chemotactic factors to bind to the cell. Our findings indicate that granule exocytosis has modulating effects upon neutrophil chemotactic responsiveness, adhesiveness, and the availability of membrane receptors for chemotactic factors.

\section{METHODS}

Materials. Ionophore A23187, provided by Robert Hamill (Eli Lilly and Co., Indianapolis, Ind.), was dissolved (10 mg/ $\mathrm{ml}$ ) in dimethyl sulfoxide (Fisher Scientific Co., Pittsburgh, $\mathrm{Pa}$.) and stored at $-20^{\circ} \mathrm{C}$ until diluted in the indicated solutions on the day of the experiment. Phorbol myristate acetate 
(PMA) ${ }^{1}$ was obtained from Consolidated Midland Corp. (Brewster, N. Y.) and dissolved in dimethyl sulfoxide. Appropriate dimethyl sulfoxide controls were evaluated for each experimental condition. Concanavalin A ( 2 times crystallized in saturated $\mathrm{NaCl}$, Miles-Yeda Laboratories, Rehovot, Israel) was dissolved in Hanks' balanced salt solution (National Institutes of Health Media Unit) at 100 times the concentration used in incubations.

Isolation of human neutrophils. Leukocyte suspensions containing over $95 \%$ neutrophils were prepared from heparinized blood of healthy volunteers by centrifugation on Hypaque (Winthrop Laboratories, New York)-Ficoll (Pharmacia Fine Chemicals, Inc., Piscataway, N. J.) followed by dextran sedimentation and hypotonic lysis of erythrocytes as described previously $(8,9)$. The resulting neutrophils were washed with Hanks' balanced salt solution before use.

Chemotaxis assay. Initial chemotaxis studies employed the ${ }^{51} \mathrm{Cr}$ radioassay of chemotaxis previously described (10). Neutrophils were incubated for $1 \mathrm{~h}$ at $37^{\circ} \mathrm{C}$ with $1 \mu \mathrm{Ci}$ of ${ }^{51} \mathrm{Cr}$ (New England Nuclear, Boston, Mass.) per $10^{6}$ cells. Two 3.0- $\mu \mathrm{m}$ cellulose nitrate filters (Sartorius, Göttingen, West Germany; distributed by Beckman Instruments Inc., Science Essentials Co., Mountainside, N. J.) were placed in the chemotactic chamber. The ${ }^{51} \mathrm{Cr}$-labeled neutrophils were washed in Hanks' medium, suspended at a density of $2.3 \times 10^{6} / \mathrm{ml}$ in Gey's tissue culture medium ( $\mathrm{pH} 7.2$ ) containing $2 \%$ bovine serum albumin, $2 \%$ penicillin, and streptomycin (Microbiological Associates, Walkersville, Md.), and then placed in the upper compartment of the chemotactic chamber. The chemotactic stimulus was placed in the lower compartment. The chambers were incubated for $3 \mathrm{~h}$ at $37^{\circ} \mathrm{C}$ in $100 \%$ humidity and $5 \% \mathrm{CO}_{2}$. Under these conditions neutrophils migrate through the upper and into the lower filter. The lower cellulose nitrate filters were then rinsed and placed in individual gamma counter vials for radioassay. The number of neutrophils migrating into the lower filter are expressed as corrected counts per minute as described previously. All assays were performed in quadruplicate and the data expressed as the mean $\pm \mathrm{SEM}$ of these four values.

In other experiments the morphologic method of Zigmond and Hirsch was used to assess neutrophil chemotaxis (11). The cells were processed as described and then suspended at a density of $2.3 \times 10^{6} / \mathrm{ml}$ in Gey's tissue culture medium (pH 7.2) containing $2 \%$ bovine serum albumin, $2 \%$ penicillin, and streptomycin. A single $3.0-\mu \mathrm{m}$ cellulose nitrate filter (Sartorius) was used and the chemotactic chambers were incubated for $\mathbf{4 5} \mathrm{min}$ as described above. The filters were then removed from the chambers, rinsed in $0.85 \%$ saline, fixed in methanol, and stained with Mayer's hematoxylin and eosin. The filters were dehydrated with increasing concentrations of ethanol, cleared with xylene, and mounted on glass slides with immersion oil. All assays were performed in duplicate. The migration front was determined by measuring the farthest distance traveled by two cells per high-powered field with a standard microscope micrometer. Five such determinations were made for each filter. Measurements from duplicate filters were pooled and the mean and standard error determined. Such pooling of data is justified because the variation of migration fronts within a single filter was greater than variation among duplicate filters (12). The mean values were compared by the Student's $t$ test.

${ }^{1}$ Abbreviations used in this paper: Con A, concanavalin A; LDH, lactic dehydrogenase; PMA, phorbol myristate acetate; PMN, polymorphonuclear leukocyte; TPCK, tosyl-L-phenylalanyl choromethane.
Chemotactic agents. Partially purified C5a was prepared by methods described previously (13). $4 \mathrm{ml}$ of fresh serum was incubated with $0.3 \mathrm{mg} / \mathrm{ml}$ of Escherichia coli $0127: \mathrm{B} 8$ endotoxin (lipopolysaccharide B, Difco Laboratories, Detroit, Mich.) for $1 \mathrm{~h}$ at $37^{\circ} \mathrm{C}$. After addition of EDTA ( $10 \mathrm{mM}$, Fisher Scientific Co.) the sample was placed on a Sephadex G-100 column which was eluted with $0.04 \mathrm{M}$ phosphate-buffered $0.85 \%$ saline, $\mathrm{pH}$ 7.4. Every third fraction was assayed for chemotactic activity. C5a eluted in the 15,000-dalton region. For some experiments sodium caseinate (Difco Laboratories), $5 \mathrm{mg} / \mathrm{ml}$ in $0.85 \% \mathrm{NaCl}$, or unfractionated $E$. coli endotoxinactivated serum (14) were used as the chemotactic stimulus. The synthetic peptide chemotactic factor f-Met-Leu-Phe (obtained from Dr. R. Freer, Department of Pharmacology, Virginia Commonwealth University, Richmond, Va.) was prepared as previously described (4). f-Met-Leu- $\left[{ }^{3} \mathrm{H}\right] \mathrm{Phe}$ with a sp act of $55 \mathrm{Ci} / \mathrm{mM}$ was a gift from Dr. R. Young, New England Nuclear. f-Nle-Leu- $\left[{ }^{3} \mathrm{H}\right] \mathrm{Phe}$ was obtained from New England Nuclear after synthesis from its precursor as already described (15). Random locomotion was assessed with Hanks' medium in the stimulus compartment.

Neutrophil orientation in response to a chemoattractant. Neutrophil orientation in response to a chemoattractant was assessed using the orientation chamber recently described by Zigmond (16). Human neutrophils prepared by the HypaqueFicoll technique were subjected to indicated manipulations, washed in Hanks' media, and then permitted to adhere to glass cover slips by incubation for $15 \mathrm{~min}$ at $37^{\circ} \mathrm{C}$ in $100 \%$ humidity. Adherent neutrophils were then placed in orientation chambers, with f-Met-Leu-Phe $(50 \mathrm{nM})$ as the chemoattractant. After a 45-min additional incubation, 100 cells were examined by phase microscopy and scored as either oriented toward the stimulus, oriented away from the stimulus, or indeterminant (no cell polarity).

Neutrophil adherence. Polymorphonuclear leukocyte (PMN) adherence to a surface was quantitated by placing 1 $\mathrm{cm}^{3}$ of ${ }^{51} \mathrm{Cr}$-labeled PMNs used for the chemotaxis studies into 16-mm diameter wells (Tissue Culture Cluster 24 well, Costar, a Division of Data Packaging Corporation, Cambridge, Mass.) followed by a 30 -min incubation at $37^{\circ} \mathrm{C}$. The wells were then drained and rinsed three times with Hanks' medium. The adherent cells were lysed by addition of $1 \mathrm{~cm}^{3}$ distilled water to the wells followed by a 30 -min agitation at room temperature. Adherence was quantitated as the amount of ${ }^{51} \mathrm{Cr}$ released by the adherent cells into the distilled water by counting a $0.5-\mathrm{cm}^{3}$ aliquot in a gamma counter. All measurements of adherence were performed in triplicate.

Cell viability. Cell viability after exposure to the various compounds was monitored by two techniques: $(a)$ the ability to exclude trypan blue dye (Grand Island Biological Co., Grand Island, N. Y.) and (b) measurements of the cytoplasmic enzyme lactic dehydrogenase $(\mathrm{LDH})$ released into the extracellular environment. Under the conditions studied in these experiments, ionophore A23187 (10 nM-1 $\mu \mathrm{M})$, PMA (0.05$50 \mathrm{ng} / \mathrm{ml}$ ), and concanavalin A (Con A; 5-100 $\mu \mathrm{g} / \mathrm{ml}$ ) did not affect cell viability.

Assessment of neutrophil receptors for the chemoattractant f-Met-Leu-Phe. Neutrophil binding of f-Met-Leu$\left[{ }^{3} \mathrm{H}\right]$ Phe was determined as recently described (6). Human neutrophils (Hypaque-Ficoll) were subjected to various manipulations, washed twice in Hanks' medium, and then suspended at $5 \times 10^{6}$ cells $/ \mathrm{ml}$ in Hanks' medium. Tosyl-L-phenylalanyl chloromethane (TPCK, Calbiochem, San Diego, Calif.) was added $(0.1 \mathrm{mM})$ to $2 \mathrm{~cm}^{3}\left(10^{7}\right)$ PMNs and then $50 \mathrm{nM}$ f-Met-Leu- $\left[{ }^{3} \mathrm{H}\right]$ Phe containing $200,000 \mathrm{cpm}$ of ${ }^{3} \mathrm{H}$ was added to the cells. Control cells contained the above plus $10 \mu \mathrm{M}$ nonradioactive peptide. The cells were then incubated on ice 
for $1 \mathrm{~h}$ with intermittent agitation. The interaction of cells with peptide was terminated by flushing $5 \times 10^{6}$ cells on to a GF/B glass fiber filter (Whatman, Inc., Clifton, N. J.) followed by washing twice with $7 \mathrm{~cm}^{3}$ of ice-cold Hanks' solution. The filters with cells were then counted in a liquid scintillation counter with $10 \mathrm{ml}$ of Aquasol (New England Nuclear) as the counting solution. Data are expressed as net (experimental - control) counts per minute per $5 \times 10^{6}$ neutrophils. Hydrolysis of $\left[{ }^{3} \mathrm{H}\right] \mathrm{N} \alpha$-formyl Nle-Leu-Phe-OH (f-NleLeu- $\left.\left[{ }^{3} \mathrm{H}\right] \mathrm{Phe}\right)$ was assessed by adding $1 \mu \mathrm{Ci}(50 \mathrm{nM})$ to cells, without TPCK, and the cells were incubated for $30 \mathrm{~min}$ at $37^{\circ} \mathrm{C}$. The reaction was terminated by addition of acetic acid (final concentration 50\%). Any debris was removed by centrifugation, the supernate was concentrated, and then assayed for hydrolytic products by thin-layer chromatography as recently described (17).

Enzyme measurements. Lysozyme activity was determined by measuring turbidometrically the rate of lysis of Micrococcus lysodeikticus (Worthington Biochemical Corp., Freehold, N. J.) at pH 6.2. Enzyme activity was expressed in terms of micrograms per milliliter egg-white lysozyme standard (Worthington Biochemical Corp.) (18, 19). $\beta$-Glucuronidase was assayed by measuring the release of phenophthalein from its $\beta$-glucuronate (Sigma Chemical Co., St. Louis, Mo.) after $4 \mathrm{~h}$ incubation at $\mathrm{pH} 4.5$. Activity was expressed as micrograms phenophthalein released/10 $7{ }^{7}$ neutrophils per $4 \mathrm{~h}(20)$. LDH was assayed by measuring the consumption of $\beta$-nicotinamide-adenine dinucleotide (NADPH, Sigma Chemical Co.) during the reaction of pyruvate to lactate. LDH activity was expressed in Wroblewski units (21). Enzyme activities were determined in incubation media or in whole cell or granule suspensions after disruption with $0.2 \%$ Triton X-100 (Rohm $\&$ Haas Co., Philadelphia, Pa.). None of the agents studied affected these enzyme assays.

Cell lysis and granule separation. Neutrophil granules were separated by continuous sucrose gradients with a modification (22) of the method of West et al. (23). Neutrophils suspended in $9 \mathrm{~cm}^{3} 0.34 \mathrm{M}$ sucrose $\left(5 \times 10^{7}\right.$ cells $\left./ \mathrm{ml}\right)$ were lysed in the presence of $1 \mathrm{~cm}^{3}$ sodium heparin $(10,000 \mathrm{U} / \mathrm{ml}$, Upjohn Co., Kalamazoo, Mich.) by repeated aspiration through a 20 -gauge, $9-\mathrm{cm}$ spinal needle until $85 \%$ of cells were lysed as indicated by phase microscopy. Lysates were then passed serially through 5 - and $2-\mu \mathrm{m}$ polycarbonate filters (Nuclepore; Neuro Probe, Inc., Bethesda, Md.) to remove unbroken cells and nuclei. Resulting granule-rich lysates $(5 \mathrm{ml})$ were layered over continuous sucrose gradients with specific gravities ranging from 1.12 to 1.28 in $1 \times 3.5$-inch cellulose nitrate tubes (Beckman Instruments, Inc., Spinco Div., Palo Alto, Calif.), then centrifuged at $95,000 \mathrm{~g}$ for $4 \mathrm{~h}$ at $4^{\circ} \mathrm{C}$. After centrifugation, gradients were pumped out $(1.0 \mathrm{ml} / \mathrm{min})$ from the bottom through a $0.8-\mathrm{mm} \times 14-\mathrm{cm}$ rigid tube inserted through the gradient and held in a fixed position against the bottom of the centrifuge tube and $1.2-\mathrm{ml}$ fractions were collected for enzyme determinations. By this technique, three granule fractions and a particulate fraction that contains enzymes characteristic of plasma membrane can be obtained. The granules have been labeled A, B, and C and it has been shown that granules A and B correspond to primary (azurophil) granules and $C$ to the secondary (specific) granules (23). The various granule fractions were pooled, diluted in $0.34 \mathrm{M}$ sucrose, pelleted by centrifugation at $27,000 \mathrm{~g}$ for $20 \mathrm{~min}$, washed twice in Hanks' medium, repelleted, and then lysed by three freeze-thaw cycles with dry ice in alcohol and a $37^{\circ} \mathrm{C}$ water bath.

Protein synthesis. The effect of the protein synthesis inhibitors cycloheximide (Sigma Chemical Co.), puromycin (Sigma Chemical Co.), and Harringtonine (the latter a generous gift from Dr. J. A. R. Mead, National Cancer Institute,
National Institutes of Health, Bethesda, Md.), on chemotaxis, secretion of lysozyme, and f-Met-Leu- $\left[{ }^{3} \mathrm{H}\right] \mathrm{Phe}$ binding was studied. The protein synthesis inhibitors were added to the cells at the indicated concentrations and the mixture was incubated for $30 \mathrm{~min}$ at $37^{\circ} \mathrm{C}$ before assessing the indicated function. In related experiments the inhibition of protein synthesis was documented by following the 30 -min cell-inhibitor incubation by another $1-\mathrm{h}$ incubation at $37^{\circ} \mathrm{C}$ in the presence of $\left[{ }^{3} \mathrm{H}\right]$ leucine (leucine, $L-\left[4,5-{ }^{3} \mathrm{H}(\mathrm{N})\right]$, New England Nuclear, $1.0 \mu \mathrm{Ci}$ per $\left.10^{6} \mathrm{PMNs}\right)$. Ice-cold trichloroacetic acid (TCA, J. T. Baker Chemical Co., Phillipsburg, N. J.) was then added so that the final concentration was $10 \%$. The resulting protein precipitate was pelleted by centrifugation, washed four times in ice-cold $10 \%$ TCA, suspended in $1.0 \mathrm{~cm}^{3}$ Hanks' buffer, and then a $0.5-\mathrm{cm}^{3}$ aliquot was dissolved in Aquasol and counted in a scintillation counter. $\left[{ }^{3} \mathrm{H}\right]$ Leucine incorporation into the TCA precipitate from cells treated with buffer was compared to cells treated with the protein synthesis inhibitors.

\section{RESULTS}

Dose-response of f-Met-Leu-Phe on chemotaxis and lysozyme secretion. We examined the effect of varying concentrations of f-Met-Leu-Phe upon chemotaxis and lysozyme secretion from cells migrating through $3.0-\mu \mathrm{m}$ cellulose nitrate filters using the radioassay of chemotaxis. The chemotactic response of human neutrophils was similar to that previously described for rabbit neutrophils (4). For chemotaxis a maximal response was noted with $0.01-0.1 \mu \mathrm{M}$ peptide (Table I). At $>0.1$ $\mu \mathrm{M}$ f-Met-Leu-Phe the chemotactic response was inhibited. In contrast, lysozyme secretion by neutrophils migrating through cellulose nitrate filters was maximal

TABLE I

Dose Response of f-Met-Leu-Phe on Chemotaxis and Lysozyme Secretion by Neutrophils in Modified Boyden Chambers*

\begin{tabular}{lcc}
\hline $\begin{array}{c}\text { Concentration of } \\
\text { f-Met-Leu-Phe }\end{array}$ & $\begin{array}{c}\text { Chemotaxis } \\
\text { (lower filter) }\end{array}$ & Lysozyme released \\
\hline & corrected cpm & \% total \\
0 & $250 \pm 15$ & $4 \pm 1$ \\
$1 \mathrm{pM}$ & $350 \pm 25$ & $4 \pm 2$ \\
$10 \mathrm{pM}$ & $250 \pm 20$ & - \\
$0.1 \mathrm{nM}$ & $300 \pm 38$ & $4 \pm 1$ \\
$1 \mathrm{nM}$ & $1,250 \pm 105$ & - \\
$10 \mathrm{nM}$ & $3,100 \pm 320$ & $6 \pm 1$ \\
$0.1 \mu \mathrm{M}$ & $2,750 \pm 255$ & $8 \pm 2$ \\
$1 \mu \mathrm{M}$ & $450 \pm 8$ & $10 \pm 1$ \\
$10 \mu \mathrm{M}$ & $180 \pm 20$ & $11 \pm 2$ \\
\hline
\end{tabular}

${ }^{*}$ Chemotactic response with the ${ }^{51} \mathrm{Cr}$-radioassay of chemotaxis. Lysozyme released into the extracellular medium by PMNs migrating through $3.0-\mu \mathrm{m}$ cellulose nitrate filters is expressed as percent of total lysozyme contained in all cells placed into the chemotactic chamber. Mean \pm SEM four determinations for chemotaxis and two experiments for enzyme release. 


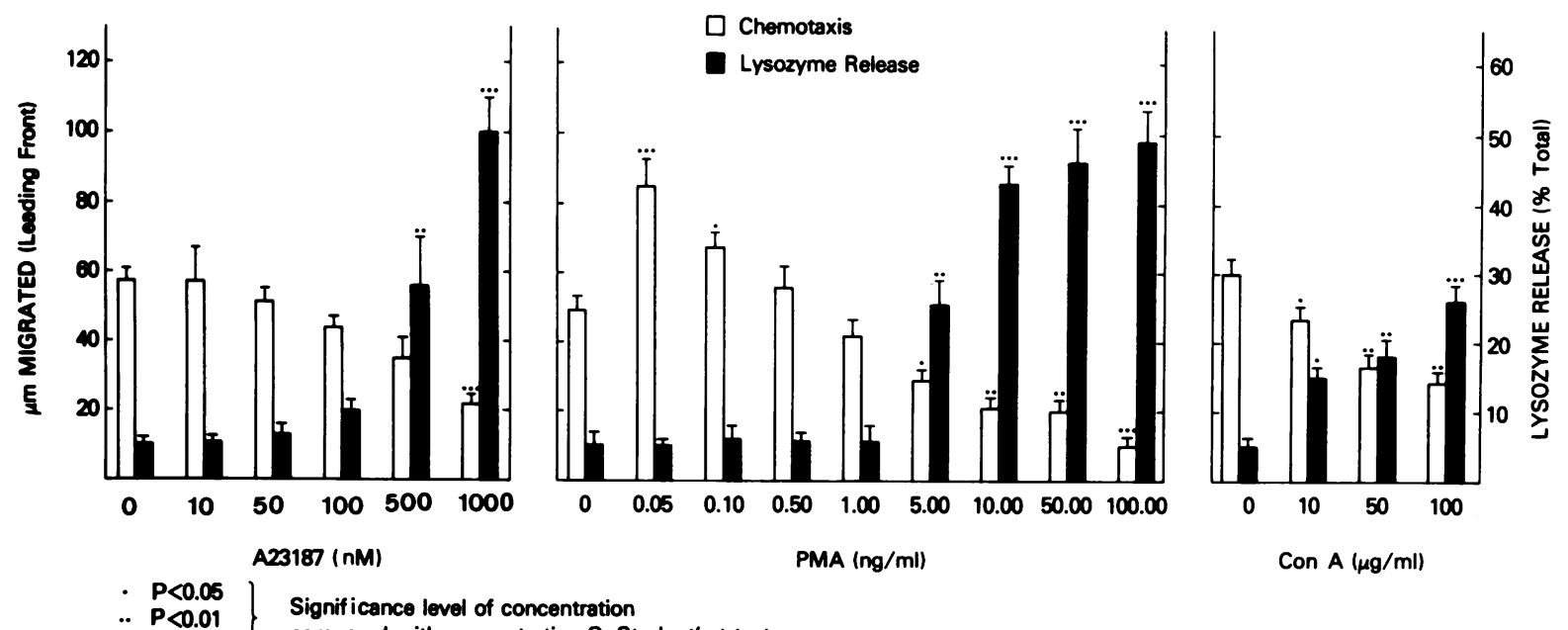

FIGURE 1 Effect of incubating neutrophils with the degranulating stimuli A23187, PMA, or Con A for $30 \mathrm{~min}$ on lysozyme release into the extracellular milieu and chemotactic responsiveness. Post-secretory cells were washed twice and chemotaxis was assayed by the leading front morphologic technique, with partially purified C5a as the chemoattractant. Mean \pm SEM, four experiments.

at concentrations of f-Met-Leu-Phe which inhibited chemotaxis.

The inverse relationship between exocytosis and neutrophil chemotaxis. Fig. 1 shows that concentrations of ionophore A23187, PMA, and concanavalin A, which induced secretion of $>30 \%$ of the total neutrophil lysozyme, significantly inhibited neutrophil chemotaxis. Less than $10 \%$ of the azurophil enzyme $\beta$-glucuronidase was released under these conditions. It is to be noted that with low concentrations of PMA $(0.05$ and $0.1 \mathrm{ng} / \mathrm{ml}$ ), conditions not associated with detectable secretion, chemotaxis was enhanced, confirming an earlier report (24).

In other studies, in which secretion was induced by exposing cells in suspension to the chemotactic peptide f-Met-Leu-Phe and cytochalasin B, and C5a was used as the chemoattractant, inhibition of locomotion was noted under conditions of lysozyme release (Fig. 2).

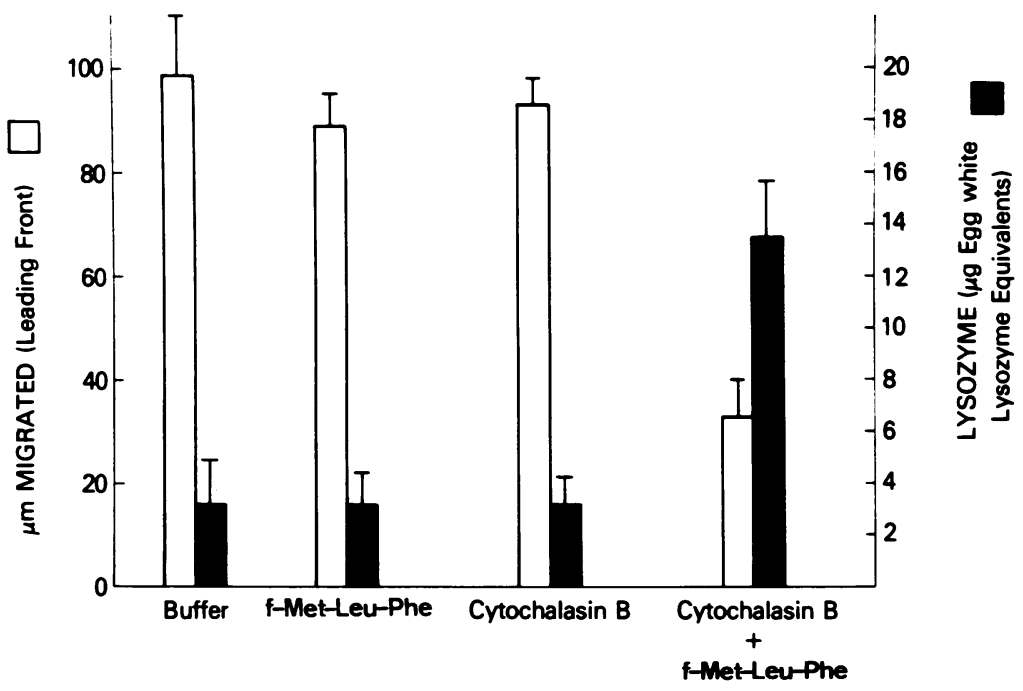

Figure 2 Effect of exposing neutrophils to cytochalasin B (5 $\mu \mathrm{g} / \mathrm{ml})$ and f-Met-Leu-Phe $(1 \mu \mathrm{M})$ on lysozyme release and chemotactic responsiveness. Lysozyme release is expressed as micrograms per egg white lysozyme equivalents (see Methods). Post-secretory cells were washed twice and chemotaxis was determined by the leading front morphologic technique, with partially purified C5a as the chemoattractant. Mean \pm SEM, four determinations. 
Less than $15 \%$ release of $\beta$-glucuronidase occurred under these conditions and there was no detectable release of the cytoplasmic enzyme lactate dehydrogenase. To test the possibility that the inhibition of locomotion after exocytosis was caused by the feedback action of a secreted granule product, neutrophil granule lysates were incubated with fresh cells which were then assessed for chemotactic responsiveness to f-MetLeu-Phe $(10 \mathrm{nM})$. As shown in Table II, incubation of neutrophils with specific granule lysates (fraction C), which contained the granule enzymes most readily released during the conditions of exocytosis, did not inhibit chemotaxis. Slight but significant $(P<0.05)$ inhibition of migration by an azurophil granule (B-granule in Table II) was noted.

The ability of cells to orient in a gradient of f-MetLeu-Phe (50 nM) after incubation with A23187, PMA, Con A, or C5a plus cytochalasin B, was assessed (Table III). After such incubation cells appeared round and did not assume their characteristic polarity in the chemoattractant gradient. Incubation with $\mathrm{C} 5 \mathrm{a}$ or cytochalasin B alone, conditions not associated with exocytosis of lysosomal granules, did not affect the ability of PMNs to orient in a gradient of f-Met-Leu-Phe.

Effect of exocytosis on neutrophil adherence. Incubation of PMNs with A23187, PMA, or f-Met-Leu-Phe plus cytochalasin $B$ increased cell adhesiveness to plastic (Table IV). Whereas $12 \%$ of control cells adhered to the plastic wells, the adherence of cells exposed to A23187 (1 $\mu \mathrm{M}$ ), PMA, Con A, or f-Met-LeuPhe $(10 \mu \mathrm{M})$ plus cytochalasin $B$ was $34,42,49$, and $38 \%$, respectively. Incubation of PMNs with cytochalasin $B$ alone reduced the percent adherent cells

TABLE II

Effect of Neutrophil Granule Lysates on Neutrophil Locomotion

\begin{tabular}{lcc}
\hline Granule fraction & Lysozyme & $\begin{array}{c}\text { Chemotaxis } \\
\text { (lower filter) }\end{array}$ \\
\hline & $\mu g / n l$ & corrected cpm \\
None (buffer) & 0 & $785 \pm 85$ \\
Azurophil granules & & \\
A & 10 & $842 \pm 38$ \\
B & 5 & $690 \pm 30$ \\
Specific granules & & \\
C & 11.5 & $891 \pm 75$ \\
\hline
\end{tabular}

* Sucrose gradient fractions identified as described in (25). Granules were obtained as described, washed in Hanks' medium, lysed by sonication and suspended with PMNs at the indicated concentration of lysozyme. After incubation for $30 \mathrm{~min}$ at $37^{\circ} \mathrm{C}$ the lysate-PMN preparations were added to chemotactic chambers with $10 \mathrm{nM}$ f-Met-Leu-Phe as the chemotactic stimulus.
TABLE III

Effect of Secretion on Neutrophil Orientation in a Gradient of f-Met-Leu-Phe

\begin{tabular}{lccc}
\hline & \multicolumn{3}{c}{ Cell orientationt } \\
\cline { 2 - 4 } \multicolumn{1}{c}{ Secretagogue* } & $\begin{array}{c}\text { Oriented } \\
\text { toward } \\
\text { stimulus }\end{array}$ & $\begin{array}{c}\text { Indeter- } \\
\text { minant }\end{array}$ & $\begin{array}{c}\text { Oriented } \\
\text { away from } \\
\text { stimulus }\end{array}$ \\
\hline None (buffer) & 63 & 30 & 7 \\
& 61 & 30 & 9 \\
A23187 (1 $\mu \mathrm{M})$ & 0 & 95 & 5 \\
PMA $(50 \mathrm{ng} / \mathrm{ml})$ & 3 & 93 & 4 \\
Con A & 1 & 99 & 0 \\
$(50 \mu \mathrm{g} / \mathrm{ml})$ & 8 & 90 & 2 \\
$(100 \mu \mathrm{g} / \mathrm{ml})$ & & & \\
C5a $(5 \mu \mathrm{g} / \mathrm{ml})$ & 27 & 56 & 17 \\
Cytochalasin B $(5 \mu \mathrm{g} / \mathrm{ml})$ & 6 & 94 & 0 \\
C5a $(5 \mu \mathrm{g} / \mathrm{ml})$ & 64 & 30 & 6 \\
$\quad+$ Cytochalasin B & 70 & 20 & 10 \\
$(5 \mu \mathrm{g} / \mathrm{ml})$ & 3 & 96 & 1 \\
\hline
\end{tabular}

* Neutrophils were exposed to the indicated substance for $30 \mathrm{~min}$ at $37^{\circ} \mathrm{C}$, the cells were then washed twice in Hanks' medium, suspended in fresh Gey's medium at a density of $2.5 \times 10^{6}$ cells $/ \mathrm{ml}$.

I Numbers represent percent of cells oriented toward the chemoattractant f-Met-Leu-Phe $(50 \mathrm{nM})$ when incubated in the presence of a chemoattractant gradient for $30 \mathrm{~min}$ at $37^{\circ} \mathrm{C}$ (see Methods). Horizontal rows represent single experiments; 100 cells counted for each experiment.

to $3 \%(P<0.001)$. PMNs incubated with f-Met-LeuPhe alone and then washed twice and suspended in fresh media adhered more than control cells $(P<0.01)$ but less well than cells exposed to f-Met-Leu-Phe plus cytochalasin B $(P<0.01)$.

Effect of secretion on binding of f-Met-Leu- $\left[{ }^{3} \mathrm{H}\right]$ Phe. As shown in Fig. 3 incubation of neutrophils with concentrations of A23187 or PMA sufficient to cause secretion of lysosomal granule contents and inhibition of chemotaxis significantly inhibited binding of f-MetLeu- $\left[{ }^{3} \mathrm{H}\right]$ Phe despite the presence of TPCK during the binding assay, an agent expected to protect the ${ }^{3} \mathrm{H}$ ligand from proteolytic degradation. Low concentrations of the two secretagogues, which induced release of less than $20 \%$ total lysozyme, had no inhibitory effect and in some experiments enhanced f-Met-Leu$\left[{ }^{3} \mathrm{H}\right] \mathrm{Phe}$ binding. This enhanced binding was often observed even without detectable lysozyme release. The time course of inhibition of f-Met-Leu- $\left.{ }^{3} \mathrm{H}\right] \mathrm{Phe}$ binding was also studied (Fig. 4). After brief exposure to the secretogogue, often before lysozyme release was 
TABLE IV

Effect of Secretion on Cell Adherence*

\begin{tabular}{lrcc}
\hline & \multicolumn{3}{c}{ Cell adherence } \\
\cline { 2 - 5 } \multicolumn{1}{c}{ Secretagogue } & $\mathrm{cpm} / 0.5 \mathrm{~cm}^{3}$ & \% adherent & $P$ value \\
\hline None & $457 \pm 37$ & 12 & - \\
$\begin{array}{l}\text { A23187 } \\
(1 \mu \mathrm{M})\end{array}$ & & & \\
$(0.1 \mu \mathrm{M})$ & $1,292 \pm 30$ & 34 & $<0.001$ \\
PMA $(20 \mathrm{ng} / \mathrm{ml})$ & $840 \pm 75$ & 22 & $<0.02$ \\
Con $\mathrm{A}(50 \mu \mathrm{g} / \mathrm{ml})$ & $1,617 \pm 89$ & 42 & $<0.001$ \\
$\begin{array}{l}\text { f-Met-Leu-Phe } \\
(10 \mu \mathrm{M})+\text { cytochalasin B } \\
(5 \mu \mathrm{g} / \mathrm{ml})\end{array}$ & $1,867 \pm 28$ & 49 & $<0.001$ \\
$\begin{array}{c}(1 \mu \mathrm{M})+\text { cytochalasin B } \\
(5 \mu \mathrm{g} / \mathrm{ml})\end{array}$ & $1,272 \pm 78$ & 33 & $<0.001$ \\
\hline
\end{tabular}

${ }^{*}{ }^{51} \mathrm{Cr}$ PMN adherence to plastic after treatment with secretagogues for $30 \mathrm{~min}$ at $37^{\circ} \mathrm{C}$ (see Methods). Mean $\pm \mathrm{SEM}$, three determinations. The cells $\left(3.0 \times 10^{6}\right)$ added to the adherence wells contained $3,844 \mathrm{cpm} / 0.5 \mathrm{~cm}^{3}$.

† Significance level between experimental and control mean values, Student's $t$ test.

detected, f-Met-Leu-Phe binding was enhanced. With more prolonged incubation and secretion of more than $30 \%$ total cellular lysozyme inhibition of $\mathrm{f}$-MetLeu-Phe binding occurred.

Although the inhibition of f-Met-Leu- $\left[{ }^{3} \mathrm{H}\right] \mathrm{Phe}$ binding could have been related in part to cell aggregation and decreased available membrane for peptide binding, the magnitude of the inhibition of binding was too great to invoke this as the sole mechanism.
For example, concentrations of PMA (5-10 ng/ml) and A23187 $(0.1 \mu \mathrm{M})$ at which binding was inhibited, are less than those required to cause significant cell aggregation as viewed by microscopy or assessed in an aggregometer. Furthermore, in studies done with cells exposed to higher concentrations of degranulating stimuli large cell aggregates did occur but these were removed by filtration of cells through four-ply surgical gauze. After this filtration, aggregates of two to five cells were seen but binding was inhibited over $90 \%$ when only $25 \%$ of cells existed as aggregates.

The effect of various concentrations of a number of other secretagogues including f-Met-Leu-Phe plus cytochalasin B, C5a plus cytochalasin B, and Con A on f-Met-Leu- $\left[{ }^{3} \mathrm{H}\right]$ Phe bindings was studied. Enhancement of f-Met-Leu-Phe binding was seen with each secretagogue when $10-15 \%$ lysozyme secretion occurred. When the data from all the experiments were pooled and plotted as a function of the amount of lysozyme released, the enhancement of f-Met-Leu$\left[{ }^{3} \mathrm{H}\right] \mathrm{Phe}$ binding with limited exocytosis was significant (Fig. 5). The inhibition of binding noted with greater than $30 \%$ lysozyme secretion was usually associated with $\beta$-glucuronidase release but this was not always the case; concentrations of PMA causing $50 \%$ lysozyme release did not cause significant $\beta$-glucuronidase release. In addition, we were unable to show decreased f-Met-Leu- $\left[{ }^{3} \mathrm{H}\right]$ Phe binding by pretreatment of cells with nonradioactive f-Met-Leu-Phe $(1-10 \mu \mathrm{M})$ plus cytochalasin B $(5 \mu \mathrm{g} / \mathrm{ml})$ when compared to PMN pretreatment with f-Met-Leu-Phe $(1-10 \mu \mathrm{M})$ without cytochalasin $B$. This was presumably because at such relatively high concentrations of f-Met-Leu-Phe too much of the nonradioactive peptide remained bound to the cell.

Additional experiments were performed to determine

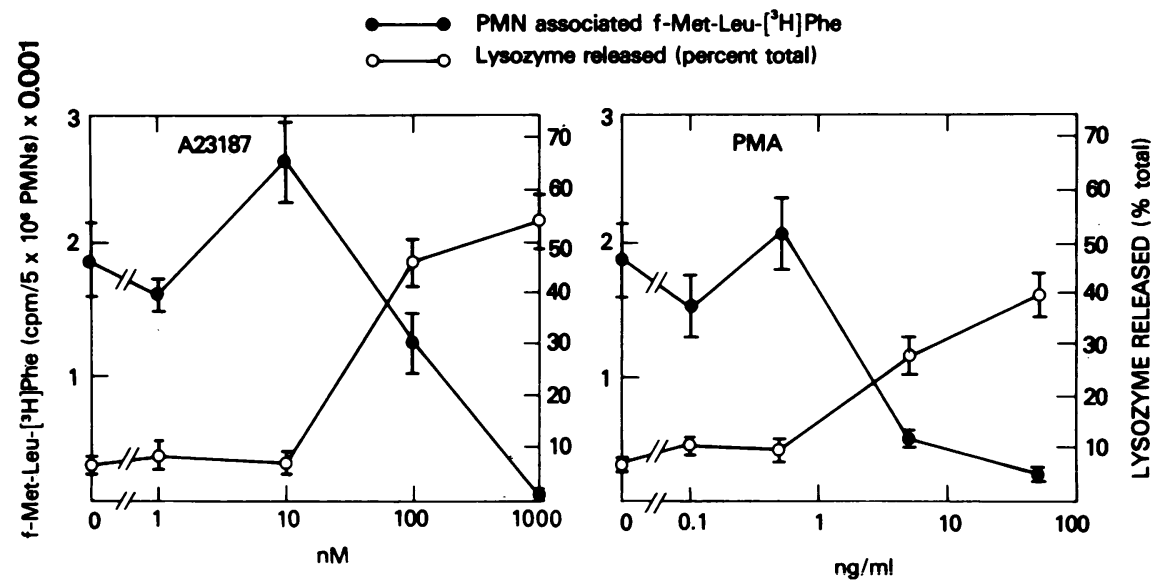

FIGURE 3 Effect of A23187 and PMA on neutrophil lysozyme release and f-Met-Leu-[ $\left.{ }^{3} \mathrm{H}\right] \mathrm{Phe}$ binding to post-secretory PMNs. Cells were incubated with the indicated concentrations of secretagogue for $30 \mathrm{~min}$, washed twice, filtered through four-ply gauze, and then the binding studies were carried out as described in Methods. Mean \pm SEM, two determinations. 

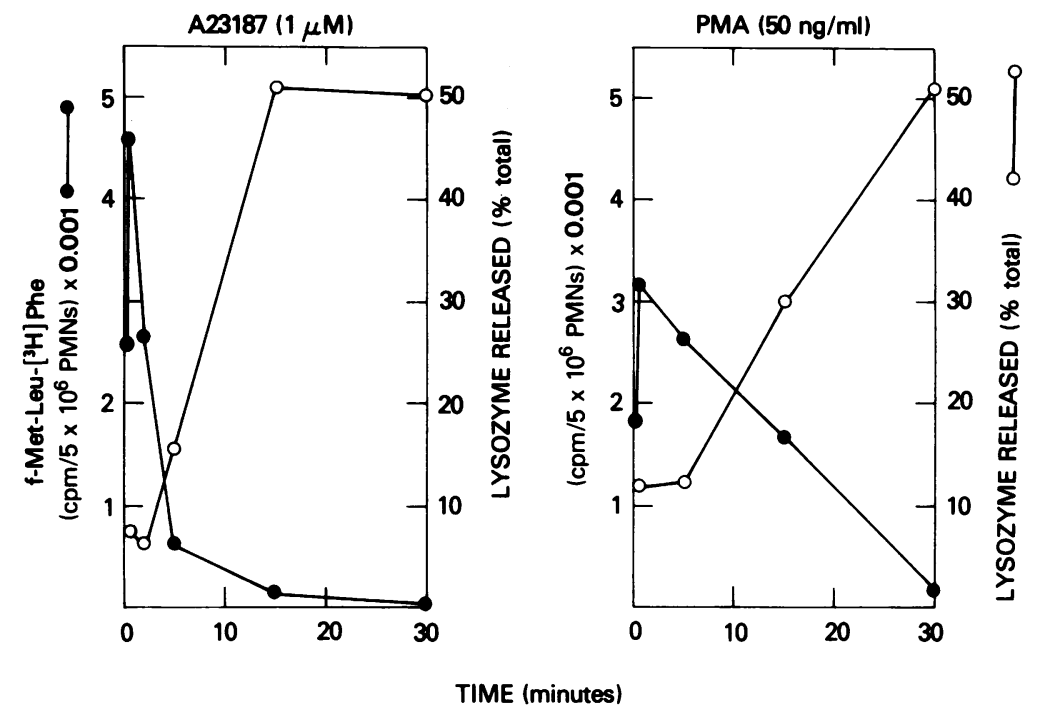

FIGURE 4 Effect of incubating PMNs with A23187 or PMA for varying amounts of time on f-Met-Leu- $\left[{ }^{3} \mathrm{H}\right]$ Phe binding. Data are the mean of duplicate determinations, one experiment.

whether the secretogogues inhibited binding by competing directly with the labeled peptide. Cells were incubated with A23187 $(1 \mu \mathrm{M})$ or PMA $(50 \mathrm{ng} / \mathrm{ml})$ for $30 \mathrm{~min}$ at $4^{\circ} \mathrm{C}$, instead of at $37^{\circ} \mathrm{C}$, or in an environment free of divalent cations, conditions that inhibited secretion. The cells were then washed in the routine manner and when assessed for f-Met-Leu- $\left[{ }^{3} \mathrm{H}\right] \mathrm{Phe}$ binding, no inhibition was observed. In other studies A23187 $(1 \mu \mathrm{M})$ or PMA $(50 \mathrm{ng} / \mathrm{ml})$ was added during binding. In contrast to nonradioactive f-Met-Leu-Phe $(10 \mu \mathrm{M})$, which competitively inhibited binding, neither A23187 nor PMA competed for f-Met-Leu- $\left[{ }^{3} \mathrm{H}\right]$ Phe binding sites.

Hydrolysis of a chemotactic peptide f-Nle-Leu$\left[{ }^{3} \mathrm{H}\right] \mathrm{Phe}$ by post-secretory cells. In the experiments shown in Fig. 5 decreased f-Met-Leu- $\left[{ }^{3} \mathrm{H}\right]$ Phe binding accompanied vigorous exocytosis, despite measures to limit ligand hydrolysis by inclusion of TPCK. To further evaluate the possibility that peptide hydrolysis contributed to the decreased binding we assessed the ability of post-secretory cells and their products to hydrolyze the related chemoattractant f-Nle-Leu$\left[{ }^{3} \mathrm{H}\right] \mathrm{Phe}$ as described in Methods. Neutrophils exposed to A23187, PMA, or f-Met-Leu-Phe plus cytochalasin B and then washed twice in Hanks' medium did not hydrolyze radiolabeled peptide differently from control cells. In contrast, cell-free supernates from post-secretory cells caused peptide hydrolysis with degradation of f-Nle-Leu-Phe to Phe and Leu-Phe residues when significant secretion of $\beta$-glucuronidase, an azurophil granule enzyme, occurred (Fig. 6). This suggested a hydrolase that could destroy the chemotactic peptide was stored in the azurophil granules. The various granule contents obtained by sucrose gradient centrifuga- tion of cell homogenates, were therefore tested for their ability to cause peptide hydrolysis. Azurophil "B" granule fractions caused significant hydrolysis of f-NleLeu- $\left[{ }^{3} \mathrm{H}\right] \mathrm{Phe}$. No hydrolysis was noted by other cellular fractions. It is noted that in other studies the hydrolytic products of f-Met-Leu-Phe, Leu-Phe, and Phe did not inhibit f-Met-Leu- $\left[{ }^{3} \mathrm{H}\right] \mathrm{Phe}$ binding.

Effect of inhibitors of protein synthesis on neutrophil chemotaxis, exocytosis, and f-Met-Leu-Phe binding. The enhanced f-Met-Leu- $\left[{ }^{3} \mathrm{H}\right] \mathrm{Phe}$ binding seen with limited exocytosis suggested that during specific granule secretion fusion of granule membrane with cytoplasmic membrane provides new membrane and possibly receptors for chemotactic factors. Such a mechanism for membrane turnover, which has been proposed to be essential for leukocyte chemotaxis (25), might occur independently of protein synthesis. Experiments were therefore designed to assess the role of protein synthesis on chemotaxis, secretion and $\mathrm{f}$ Met-Leu-Phe binding. As shown in Fig. 7, concentrations of three different inhibitors of protein synthesis that blocked $\left[{ }^{3} \mathrm{H}\right]$ leucine incorporation into TCA-precipitable protein had no significant effect on chemotactic responses to $E$. coli endotoxin-activated serum. Similarly the same concentration of protein synthesis inhibitors did not inhibit exocytosis in response to the secretagogues A23187 $(0.1 \mu \mathrm{M})$ or f-Met-Leu-Phe (1 $\mu \mathrm{M})$ plus cytochalasin $\mathrm{B}(5 \mu \mathrm{g} / \mathrm{ml})$ and had no effect on f-Met-Leu- $\left[{ }^{3} \mathrm{H}\right]$ Phe binding.

\section{DISCUSSION}

Our findings indicate that the chemotactic responsiveness of human neutrophils is influenced significantly 


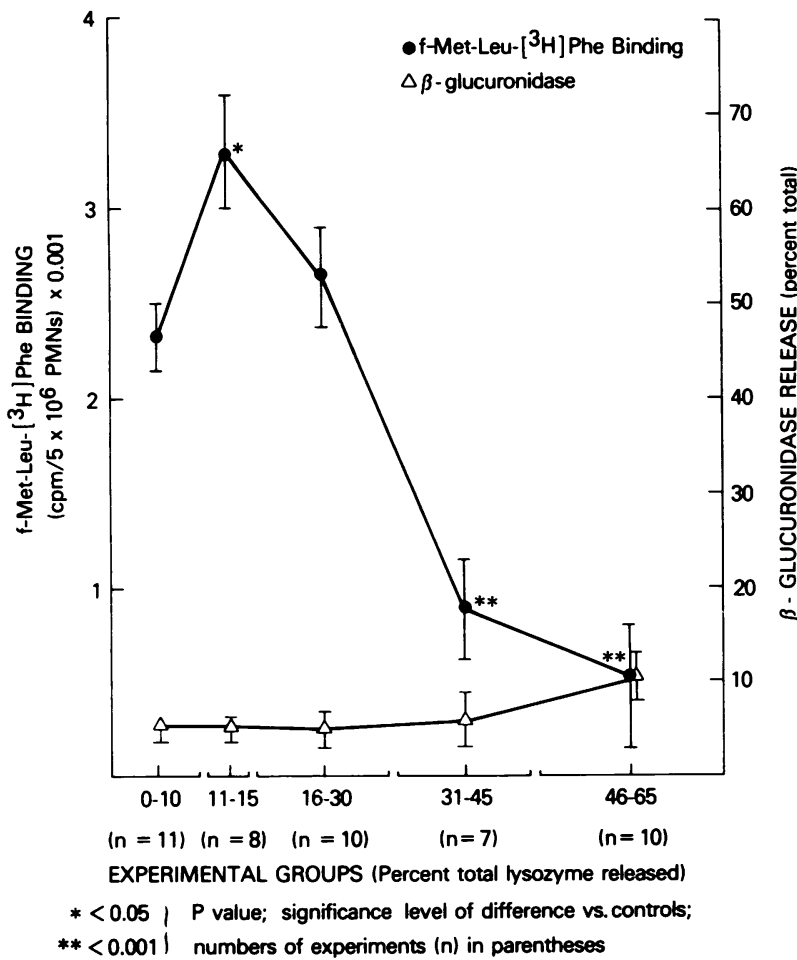

FIGURE 5 Composite data relating degranulation by all the secretagogues studied (see text) to lysosomal enzyme release and f-Met-Leu- $\left[{ }^{3} \mathrm{H}\right] \mathrm{Phe}$ binding. The data were arbitrarily grouped by the percent total lysozyme release as indicated and the data represent mean \pm SEM of the number of experiments shown in parentheses. $P$ values are the significance level of difference from controls, Student's $t$ test.

by the exocytosis of cytoplasmic granules. In studies with varying concentrations of the chemoattractant $f$ Met-Leu-Phe, it was found that concentrations of chemoattractant optimal for inducing granule exocytosis are greater than concentrations optimal for chemotaxis and that the higher concentrations actually inhibit chemotaxis, confirming previous findings of others (4). These initial studies suggested that inhibition of chemotaxis was related to secretion of granule associated enzymes.

In later experiments it was found that incubation of neutrophils with degranulating stimuli, under conditions sufficient to cause secretion of more than $30 \%$ cellular lysozyme, inhibited chemotaxis and impaired the ability of post-secretory cells to orient in a gradient of chemoattractant and to bind radiolabeled chemotactic peptide. These findings, together with our recent observation that the membrane hyperpolarization induced by chemotactic factor is inhibited by degranulating stimuli (26), indicate that the depressed chemotaxis in post-secretory cells involves the first step of the chemotactic response; i.e., the interaction of the chemotactic factor with the cell. Whether the decreased binding of chemoattractant by post-secretory cells is the re-
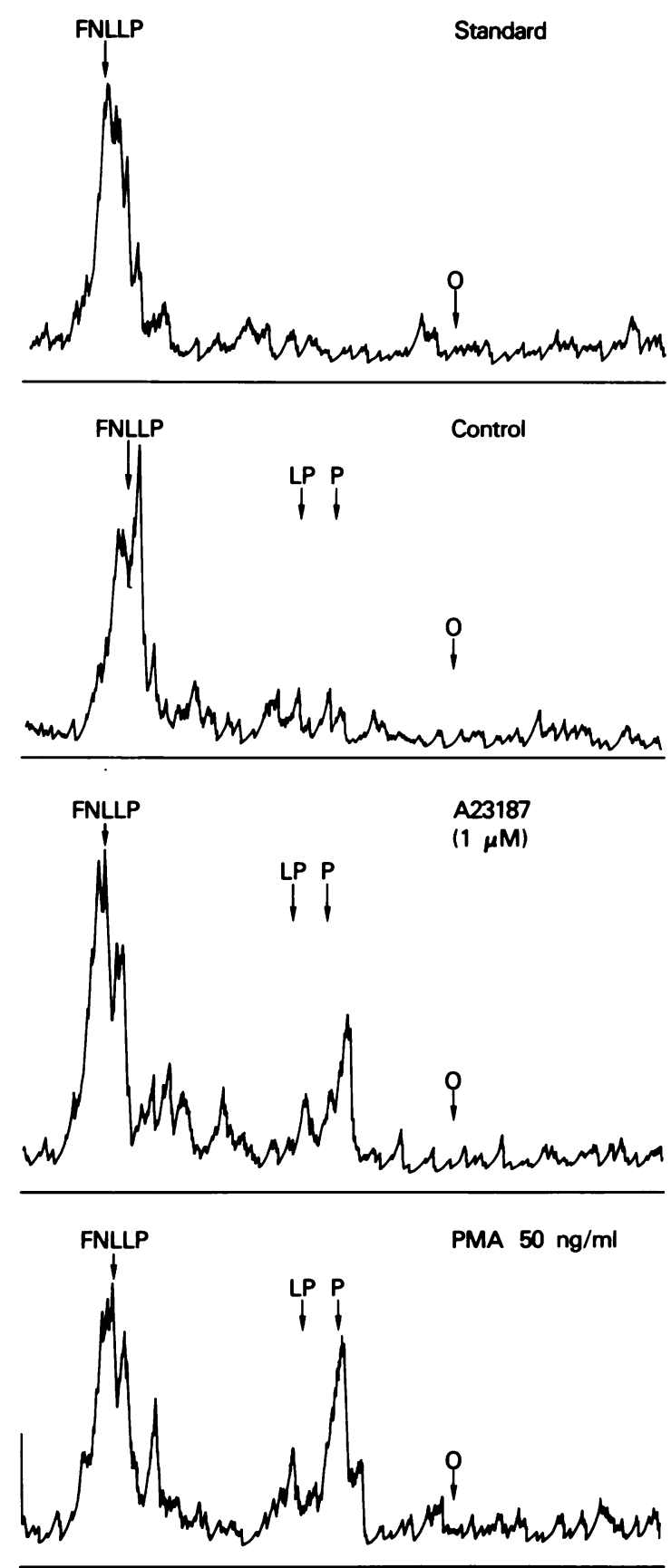

FIGURE 6 Hydrolysis of f-Nle-Leu- $\left[{ }^{3} \mathrm{H}\right]$ Phe (FNLLP) by PMN post-secretory products. Panels show ${ }^{3} \mathrm{H}$ distribution on thinlayer chromatography plates of control peptide standard FNLLP incubated in experimental medium (upper panel) or peptide exposed to medium from cells incubated $30 \mathrm{~min}$ in control medium, A23187 or PMA (lower three panels). $O$ indicates the origin, and $P$ and LP represent the migration of Phe and Leu-Phe standards, respectively. It is noted that in this experiment cells incubated with A23187 released $65 \%$ total lysozyme, $20 \% \beta$-glucuronidase, and $10 \% \mathrm{LDH}$; cells exposed to PMA release $70 \%$ lysozyme, $38 \% \beta$-glucuronidase, and $12 \% \mathrm{LDH}$ whereas control cells released $6 \%$ lysozyme, $5 \% \beta$-glucuronidase, and 3\% LDH. 


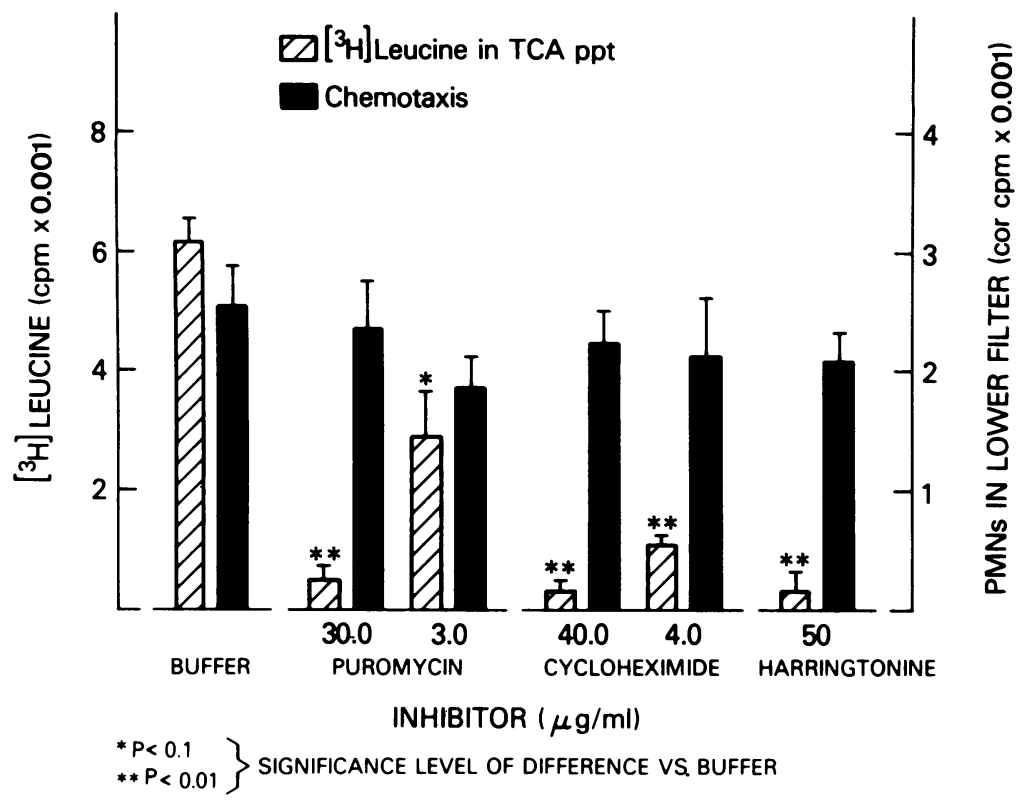

FIGURE 7 Effect of puromycin, cycloheximide, and Harringtonine on $\left[{ }^{3} \mathrm{H}\right]$ leucine incorporation into TCA-precipitable protein (TCA ppt) and on chemotaxis as measured with the ${ }^{51} \mathrm{Cr}$-radioassay. Mean $\pm S E M$, three determinations. Cor cpm, corrected counts per minute.

sult of destruction, shedding, internalization, or conformational change of existing receptors is not clear from these studies.

In addition to the decrease in the capacity of postsecretory neutrophils to respond to a chemotactic stimulus, there is evidence that the chemoattractants themselves may be inactivated by the secreted contents of the granules. We have shown that products of neutrophil secretion include at least two C5a inactivators that are stored in the azurophil granules of neutrophils and are released under conditions of vigorous exocytosis (27). It is of interest in this regard that after vigorous exocytosis, with release of the azurophil granule enzyme $\beta$ glucuronidase, secretory products are found that also hydrolyze the synthetic peptide f-Nle-Leu-Phe and appear to be derived from the azurophil granules.

Release from PMNs of a neutrophil-immobilizing factor has been reported to cause irreversible inhibition of neutrophil migration but no inhibition of cell adherence or phagocytosis $(28,29)$. We did not, however, detect a neutrophil-immobilizing factor in isolated specific granules; the granule population whose contents were preferentially released during our incubation conditions. Depressed PMN chemotactic responsiveness has also recently been reported to result from exposure of neutrophils to purified human lysozyme (30). However, the concentration of lysozyme required to inhibit locomotion appears to be too high (30-200 $\mu \mathrm{g} / \mathrm{ml}$ ) to explain the inhibition of chemotaxis seen under our experimental conditions. Increased cell adhesiveness, which we have shown to accompany exocytosis of neutrophil granules, confirming previous reports $(31,32)$, has also been associated with depression of neutrophil locomotion (32). Inhibition of chemotaxis accompanying vigorous exocytosis can thus be related to multiple phenomena: alterations of the cytoplasmic membrane with increased cell adhesiveness and decreased binding of chemoattractant as well as inactivation of chemotactic factors by lysosomal products secreted extracellularly.

During our experiments we were impressed by the enhanced binding of the chemotactic peptide f-MetLeu- $\left[{ }^{3} \mathrm{H}\right] \mathrm{Phe}$ to the cell when only $10-15 \%$ of the total cellular lysozyme was released. Exocytosis of specific granules is associated with fusion of the granule membrane with the cytoplasmic membrane and this may provide a mechanism for membrane turnover during chemotaxis. A possible role of cytoplasmic membrane turnover during leukocyte chemotaxis has been discussed recently by Stossel who suggested that synthesis of new membrane or fusion of granule membranes with the plasma membrane could be mechanisms for new membrane turnover and replenishment of cytoplasmic membrane receptors (25). Our data on enhanced f-MetLeu-Phe binding with secretion of 10-15\% lysozyme content are consistent with the latter suggestion, although it is to be noted that in some experiments f-Met-Leu- $\left[{ }^{3} \mathrm{H}\right]$ Phe binding was enhanced before detectable enzyme release. Therefore, the enhanced binding could also be related to membrane events that are independent of secretion. Moreover, we were unable to show that inhibitors of protein syn- 
thesis decreased chemotaxis, secretion of lysosomal granules, or f-Met-Leu-Phe binding. Protein synthesis, therefore, does not appear to be necessary for these events. These considerations suggest that inhibition of chemotaxis in post-secretory cells may result, in part, from a depletion of the source of available new membrane. Alternatively, the enhanced chemotaxis observed in the presence of low concentrations of cytochalasin B $(13,33)$ may be related to the mobilization of chemoattractant receptors which is postulated to occur with minimal secretion.

It is evident that neutrophil chemotactic responses and the mobilization and exocytosis of neutrophil granules are closely interrelated. The coordination of these cellular processes would appear to be critical components of host defenses. The possibility that some of the reported neutrophil chemotactic defects or the mechanism of action of some antiinflammatory agents is related to these processes is intriguing and worthy of further study.

\section{ACKNOWLEDGMENTS}

The authors acknowledge the technical assistance of Mrs. Rhoda Hubert and the helpful discussion with, and statistical advice of, Dr. David Alling.

\section{REFERENCES}

1. Goldstein, I. M., S. Hoffstein, J. I. Gallin, and G. Weissmann. 1973. Mechanisms of lysosomal enzyme release from human leukocytes: Microtubule assembly and membrane fusion induced by a component of complement. Proc. Natl. Acad. Sci. U. S. A. 70: 2916-2920.

2. Becker, E. L., H. J. Showell, P. M. Henson, and L. S. Hsu. 1974. The ability of chemotactic factors to induce lysosomal enzyme release. I. The characteristics of the release, the importance of surfaces and the relation of enzyme release to chemotactic responsiveness. $\mathrm{J}$. Immunol. 12: 2047-2054.

3. Zurier, R. B., S. Hoffstein, and G. Weissmann. 1973. Cytochalasin B: Effect on lysosomal enzyme release from human leukocytes. Proc. Natl. Acad. Sci. U. S. A. 70: 844848.

4. Showell, H. J., R. J. Freer, S. H. Zigmond, E. Schiffmann, S. Aswankumar, B. Corcoran, and E. L. Becker. 1976. The structure activity relations of synthetic peptides as chemotactic factors and inducers of lysosomal enzyme secretion for neutrophils.J. Exp. Med. 143: 11541169.

5. Becker, E. L. 1976. Some interrelations of neutrophil chemotaxis, lysosomal enzyme secretion, and phagocytosis as revealed by synthetic peptides. Am.J. Pathol. 85: 385394.

6. Aswanikamar, S., B. Corcoran, E. Schiffmann, A. R. Day, R. J. Freer, H. J. Showell, and E. L. Becker. 1977. Demonstration of a receptor on rabbit neutrophils for chemotactic peptides. Biochem. Biophys. Res. Commun. 74: 210-217.

7. Williams, L. T., R. Snyderman, M. L. Pike, and R. J. Lefkowitz. 1977. Specific receptor sites for chemotactic peptides on human polymorphonuclear leukocytes. Proc. Natl. Acad. Sci. U. S. A. 74: 1204-1208.
8. Böyum, A. 1968. Isolation of mononuclear cells and granulocytes from human blood. Isolation of mononuclear cells by one centrifugation and of granulocytes by combining centrifugation and sedimentation at $1 \mathrm{~g}$. Scand. J. Clin. Lab. Invest. Suppl. 97: 77-89.

9. Clark, R. A., and H. R. Kimball. 1971. Defective granulocyte chemotaxis in the Chediak-Higashi syndrome. J. Clin. Invest. 50: 2645-2652.

10. Gallin, J. I., R. A. Clark, and H. R. Kimball. 1973. Granulocyte chemotaxis: An improved in vitro assay employing ${ }^{51} \mathrm{Cr}$-labeled granulocytes. J. Immunol. 110: 233-240.

11. Zigmond, S. H., and J. G. Hirsch. 1973. Leukocyte locomotion and chemotaxis: New methods for evaluation and demonstration of a cell-derived chemotactic factor. J. Exp. Med. 137: 387-410.

12. Clark, R. A. F., J. I. Gallin, and A. P. Kaplan. 1975. The selective eosinophil chemotactic activity of histamine. J. Exp. Med. 142: 1462-1476.

13. Gallin, J. I., and A. S. Rosenthal. 1974. The regulatory role of divalent cations in human granulocyte chemotaxis. Evidence for an association between calcium exchanges and microtubule assembly. J. Cell Biol. 62: 594-609.

14. Gallin, J. I., R. A. Clark, and M. M. Frank. 1975. Kinetic analysis of chemotactic factor generation in human serum via activation of the classical and alternate complement pathways. Clin. Immunol. Immunopathol. 3: 334-346.

15. Day, A. R., J. A. Radding, R. J. Freer, H. J. Showell, E. L. Becker, E. Schiffmann, B. Corcoran, S. Aswanikumar, and C. B. Peri. 1977. Synthesis and binding characteristics of an intrinsically radiolabeled chemotactic acyl tripeptide. $\mathrm{N} \alpha$-Formyl-norleucyl-leucyl-phenylalanine. FEBS (Fed. Eur. Biochem. Soc.) Lett. 77: 291-294.

16. Zigmond, S. H. 1977. Ability of polymorphonuclear leukocytes to orient in gradients of chemotactic factors. $J$. Cell Biol. 75: 606-616.

17. Aswanikumar, S., E. Schiffmann, B. A. Corcoran, and S. M. Wahl. 1976. Role of a peptidase in phagocyte chemotaxis. Proc. Natl. Acad. Sci. U. S. A. 73: 2439-2442.

18. Wright, D. G., and S. E. Malawista. 1972. The mobilization and extracellular release of granular enzymes from human leukocytes during phagocytosis. J. Cell Biol. 53: 788-797.

19. Smolelis, A. N., and S. E. Hartsell. 1949. The determination of lysozyme. J. Bacteriol. 58: 731-736.

20. Talalay, P., W. H. Fishman, and C. Haggins. 1946. Chromagenic substrates. II. Phenolphthalein glucuronic acid as substrate for the assay of glucuronidase activity. J. Biol. Chem. 166: 757-772.

21. Bergmeyer, H. U., editor. 1963. Methods in Enzymatic Analysis. Academic Press, Inc., New York. 737-739.

22. Wright, D. G., D. A. Bralove, and J. I. Gallin. 1977. The differential mobilization of human neutrophil granules. Effects of phorbol myristate acetate and ionophore A23187. Am. J. Pathol. 87: 273-284.

23. West, B. C., A. S. Rosenthal, N. A. Gleb, and H. R. Kimball. 1974. Separation and characterization of human neutrophil granules. Am. J. Pathol. 77: 41-66.

24. Estensen, R. D., H. R. Hill, P. G. Quie, N. Hogan, and N. D. Goldberg. 1973. Cyclic GMP and cell movement. Nature (Lond.). 245: 458-460.

25. Stossel, T. P. 1978. The mechanism of leukocyte locomotion. In Leukocyte Chemotaxis: Methods, Physiology and Clinical Implications. J. I. Gallin and P. G. Quie, editors. Raven Press, New York. 143-160.

26. Seligmann, B., E. K. Gallin, D. L. Martin, W. Shain, and J. I. Gallin. 1977. Evidence for membrane potential changes in human polymorphonuclear leukocytes during 
exposure to the chemotactic factor f-met-leu-phe as measured with the fluorescent dye dipentyloxacarbocyanine. J. Cell Biol. 75: 103a. (Abstr.)

27. Wright, D. G., and J. I. Gallin. 1977. A functional differentiation of human neutrophil granules: Generation of C5a by a specific (secondary) granule product and inactivation of $\mathrm{C5}$ a by azurophil (primary) granule products. J. Immunol. 119: 1068-1076.

28. Goetzl, E. J., and K. F. Austen. 1972. A neutrophil-immobilizing factor derived from human leukocytes. Generation and partial characterization. J. Exp. Med. 136: 1564-1580.

29. Goetzl, E. J., I. Gigli, S. Wasserman, and K. F. Austen. 1973. A neutrophil immobilizing factor derived from human leukocytes. II. Specificity of action on polymor- phonuclear leukocyte mobility. J. Immunol. 111: 938945.

30. Gordon, L. I., S. D. Douglas, N. E. Kay, O. Yamada, E. Osserman, and H. S. Jacob. 1978. Modulation of inflammation by lysozyme. Clin. Res. 26: 554a. (Abstr.)

31. Lackie, J. M. 1977. The aggregation of rabbit polymorphonuclear leukocytes: Effects of agents which affect the acute inflammatory response and correlation with secretory activity. Inflammation. 2: 1-15.

32. Fehr, J., and C. Dahinden. 1978. The modulating influence of chemotactic factor-induced cell adhesiveness upon granulocyte function. Clin. Res. 26: 346a. (Abstr.)

33. Becker, E. L., A. T. Davis, R. D. Estensen, and P. G. Quie. 1972. Cytochalasin B. IV. Inhibition and stimulation of chemotaxis of rabbit and human polymorphonuclear leukocytes. J. Immunol. 108: 396-402. 